\title{
Delayed or Missed Diagnosis of Cervical Instability after Traumatic Injury: Usefulness of Dynamic Flexion and Extension Radiographs
}

\author{
Chang Gi Yeo, Ikchan Jeon, Sang Woo Kim \\ Department of Neurosurgery, Yeungnam University College of Medicine, Daegu, Korea
}

Prompt and accurate diagnosis of cervical spine injury is important to prevent the catastrophic results that can be caused by undetected lesions. Delayed or missed diagnosis of cervical spine injury occurs with an incidence of 5 to $20 \%$ according to previous studies. In this study, we report four cases of cervical instability without initial radiologic evidence. These cases demonstrate that dynamic flexion and extension radiographies can be a proper choice of modality to diagnose and exclude the possibility of cervical instability in a patient with a suspicious ligament injury on the static radiographies following acute cervical trauma.

Key Words: Cervical vertebrae $\cdot$ Dislocation $\cdot$ Radiography

\section{INTRODUCTION}

Prompt and accurate detection of traumatic cervical spine lesion is important, because delayed or missed diagnosis might lead to catastrophic consequences for patients, ranging from minor neurological deficits to complete tetraplegia ${ }^{1,5}$. The incidence of delayed or missed diagnosis of cervical spine injury is between 4.9 to $20 \%{ }^{3,6,8}$. There has been a reduction in the incidence of delayed or missed diagnosis in recent years with developments in radiological diagnostic examination tools including computed tomography (CT) scan and magnetic resonance (MR) imaging. Nevertheless, incomplete radiological studies and misinterpretation are still common causes of delayed or missed diagnosis ${ }^{6}$. In addition, suspicion of an injury of the posterior cervical ligament complex using only static radiographies, including MR imaging, may be insufficient to permit an exact diagnosis and determine proper management.

\section{CASE REPORT}

Four patients were diagnosed with cervical instability several

- Received: April 21, 2015 - Revised: August 11, 2015

- Accepted: August 13, 2015

Corresponding Author: Sang Woo Kim, MD, PhD

Department of Neurosurgery, Yeungnam University College of Medicine,

170, Hyeonchung-ro, Nam-gu, Daegu 42415, Korea

Tel: +82-53-620-3790, Fax: +82-53-620-3770

E-mail:sw902@ynu.ac.kr

@This is an Open Access article distributed under the terms of the Creative Commons Aftribution Non-Commercial License (http://creativecommons.org/ licenses/by-nc/3.0/) which permits unrestricted non-commercial use, distribution, and reproduction in any medium, provided the original work is properly cited. days to weeks following traffic accidents. All patients presented persistent neck pain without neurological deterioration or radiological abnormalities on static radiographies, with the exception of one case of spinous process fracture that did not involve lamina in the initial work-up. The clinical features of the enrolled patients are summarized in Table 1.

The first case was a 57-year-old woman presenting with multiple trauma caused by a rollover motor vehicle accident. She complained of left shoulder and neck pain, and was diagnosed with multiple fractures in the upper and lower extremities. A spinous process fracture was identified on $\mathrm{C} 5$ without involving lamina under routine X-ray (Fig. 1C and D, including antero-posterior, lateral, and open mouth views) and CT scan (Fig. 1A). The patient was found to have suspicious posterior ligament complex injuries including inter- and supra-spinous ligaments and ligamentum flavum on T2 fat suppression sagittal MR imaging (Fig. 1B). We decided to prescribe for the patient a conservative treatment, because of a low possibility of instability with the above radiological examination under the Subaxial Cervical Injury Classification (SLIC) ${ }^{11)}$. She complained of intermittent neck pain and discomfort during follow-up periods at the outpatient department. Subluxation of the facet joint on C5-6 was identified by dynamic flexion and extension radiographies after 9 weeks. The anterior longitudinal ligament (ALL) and intervertebral disc presented intact, and only a posterior column injury was observed. She underwent posterior fusion on C5-6 with a lateral mass screw system and interspinous wiring (Fig. 1E and F).

The second case was a 46-year-old man who was transferred to our outpatient department under the impression of subluxation of the facet joint on C5-6 after a motor vehicle accident. He had been admitted 7 weeks previously to another 
Table 1. Clinical features of all patients

\begin{tabular}{|c|c|c|c|c|c|c|c|}
\hline $\begin{array}{l}\text { Patients } \\
\text { (Age/Sex) }\end{array}$ & $\begin{array}{c}\text { Level of } \\
\text { subluxation }\end{array}$ & $\begin{array}{l}\text { The interval between } \\
\text { diagnosis and initial injury }\end{array}$ & $\begin{array}{c}\text { Initial } \\
\text { SLIC }^{*} \text { Score }\end{array}$ & $\begin{array}{l}\text { Initial Frankel's grade } \\
\text { (postop.) }\end{array}$ & $\begin{array}{l}\text { Neck motion range } \\
\text { on dynamic views }\end{array}$ & $\begin{array}{l}\text { Other bony abnormality } \\
\text { on static view }\end{array}$ & Operation \\
\hline 1 (57/F) & C5-6 & 9 weeks & $\begin{array}{c}1 \\
\text { (Intermediate } \\
\mathrm{DLC}^{+} \text {injury) }\end{array}$ & $E(E)$ & 45.4 & $\begin{array}{l}\text { C5 Spinous process } \\
\text { fracture }\end{array}$ & Posterior \\
\hline $2(46 / M)$ & C5-6 & 7 weeks & $\begin{array}{c}1 \\
\text { (Intermediate } \\
\text { DLC injury) }\end{array}$ & $E(E)$ & 12.6 & Non & Anterior \\
\hline $3(61 / M)$ & $C 4-5$ & 3 days & $\begin{array}{c}2 \\
\text { (disrupted } \\
\text { DLC injury) }\end{array}$ & $E(E)$ & 15.6 & $\begin{array}{l}\text { Kyphosis /widening of } \\
\text { interspinous space on } \\
\text { C4-5 }\end{array}$ & Posterior \\
\hline $4(56 / F)$ & $C 4-5$ & 3 days & $\begin{array}{c}1 \\
\text { (Intermediate } \\
\text { DLC injury) }\end{array}$ & $E(E)$ & 10.4 & Straightening & Posterior \\
\hline
\end{tabular}

${ }^{*}$ SLIC: Subaxial cervical injury classification system, ${ }^{\dagger}$ DLC: Disco-ligamentous complex
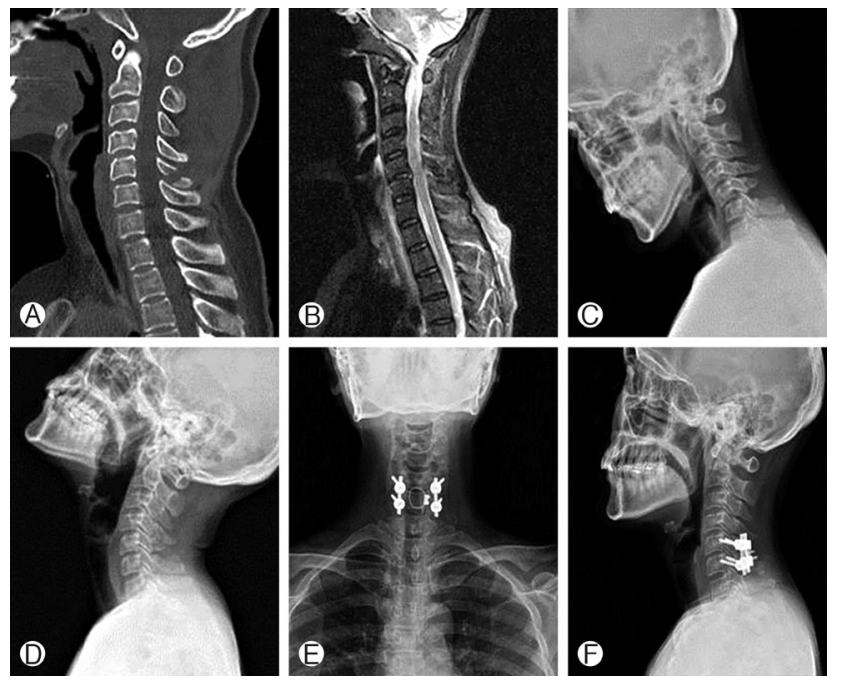

Fig. 1. One of our patients $\left(1^{\text {st }}\right)$ showing cervical instability. CT scan (A) and T2 fat suppression sagittal MR image (B) at the time of initial injury present a $\mathrm{C} 5$ spinous process fracture and high signal intensity around fracture site which suggest suspicious posterior ligament complex injury. Dynamic flexion and extension views (C, D) on 9 weeks later following the injury show subluxation on C5-6. The patient was underwent posterior fusion on C5-6 with lateral mass screw system and inter-spinous wiring $(E, F)$.

medical center with neck pain caused by the accident, and had been diagnosed with cervical sprain under CT scan, MR imaging, and cervical X-ray including antero-posterior and lateral views. No definite acute fracture line or other deformity was visible, but only subtle high signal intensity was present at the posterior ligament complex including inter- and supraspinous ligaments on T2 fat suppression sagittal MR imaging. However, his neck pain persisted, and follow-up CT scan and dynamic flexion and extension radiographies presented a subluxation on C5-6. The injury of ALL was also noted on follow-up
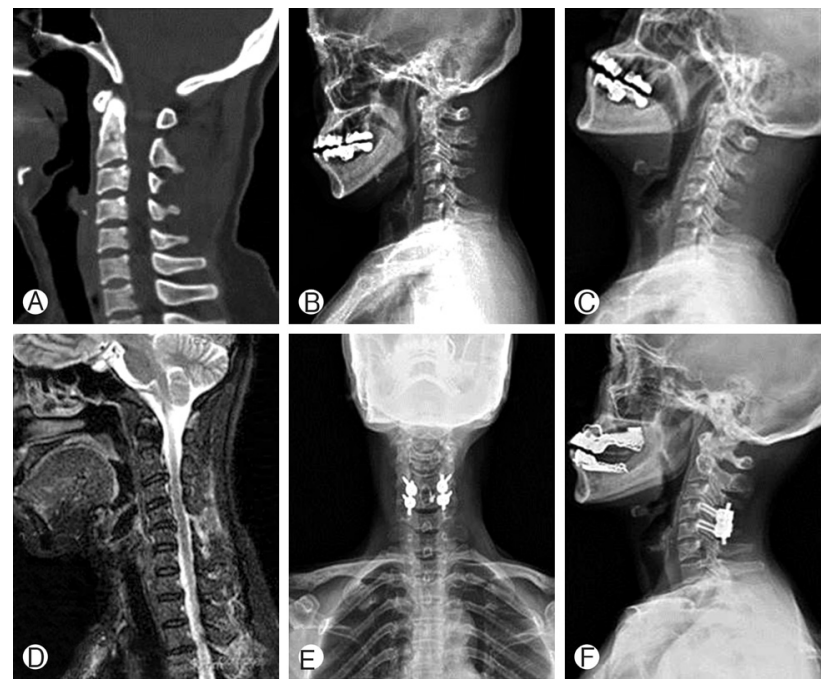

Fig. 2. The other patient $\left(4^{\text {th }}\right)$ showing cenvical instability. CT scan (A) at the time of initial injury present suspicious mild kyphosis on C4-5. Dynamic flexion and extension views $(B, C)$ on 3 days later following the injury show subluxation on C4-5. Although an inadequate dynamic study with decreased amount of motion range (10.4 degree) caused by neck pain and muscle spasm, cervical instability could be assessed. There was high signal intensity at C4-5 posterior structure on T2 fat suppression sagittal MR image (D), which suggests posterior ligament complex injury. The patient was underwent posterior fusion on $\mathrm{C} 4-5$ with lateral mass screw system and inter-spinous wiring $(E, F)$.

MRI. He initially underwent anterior cervical discectomy and fusion with plate on $\mathrm{C} 5-6$, and additional posterior fusion was considered if sustained instability was observed during the follow-up period. Fortunately, no further instability was present by the 26-month.

The third and fourth cases were a 61-year-old man and his 56-year-old wife, who visited our emergency room with mild neck pain. The couple experienced the same car accident, 
and they received the similar radiological findings of a mild focal kyphosis on C4-5 and straightening of cervical spine under routine X-ray and CT scan (Fig. 2A) without dynamic flexion and extension radiographies. There were no acute fracture lines related to the patients' symptoms. They had undergone a conservative treatment with cervical collar and without performing MR imaging. The patients complained of persistent neck pain, and the symptom was exacerbated under the condition of weight-bearing posture such as sitting or standing. Dynamic flexion and extension radiographies (Fig. 2B and C) were performed 3 days after the accident; they showed subluxation of the facet joint on C4-5 on both patients. There were suspicious posterior ligament complex injuries including inter- and supra-spinous ligaments and ligamentum flavum on T2 fat suppression sagittal MR imaging (Fig. 2D). ALL and intervertebral disc presented as intact in both patients, and posterior column injury was regarded as the main lesion. Both patients underwent posterior fusion on C4-5 with a lateral mass screw system and inter-spinous wiring (Fig. 2E and F).

\section{DISCUSSION}

The patients with cervical spine injury presenting with neck pain require radiological examination, even if the neurological examination shows normal condition ${ }^{2}$. In a disco-ligamentous injury, 30\% of patients with ligamentous disruption displayed a negative result on static radiographies and CT scan, and it was identified by subsequent MR imaging ${ }^{10)}$. However, MR imaging as a screening tool has not been definitively shown to be cost-effective in initial evaluation, and the indications are also less clear for detecting instability ${ }^{10)}$. The majority of patients with posterior ligament complex injury that has been noted on MR imaging do not require surgical stabilization ${ }^{10)}$. It is an important point that MR imaging findings cannot be an absolute factor to identify cervical instability. In addition, the healing of once-injured posterior ligament complex is usually less predictable in adult patients than that of bone healing, and progressive instability and deformity are possible ${ }^{11}$. Assessment of the integrity of the disco-ligament complex is a critical and independent component of surgical decision- making.

In this study, all patients presented a flexion-distraction injury with bilateral facet subluxation. There were varying degrees of disco-ligamentous complex injuries, ranging from only posterior ligamentous structures to additional posterior annulus of disc, which have a higher risk of instability leading to translation and dislocation and require surgical treatment. These lesions could not be identified with static radiological studies until dynamic flexion and extension radiographies were applied. From these cases, we can expect that the most impor- tant reason for developing delayed or missed diagnosis of cervical instability was an incomplete set of radiographies, and MR imaging did not act as a crucial diagnostic modality. The application of dynamic flexion and extension radiographies can be a helpful diagnostic tool to rule out instability.

Dynamic flexion and extension radiographies are often recommended for patients complaining of neck pain or tenderness after an acceleration-deceleration mechanism injury, especially for patients presenting persistent symptoms in the absence of abnormal findings on standard 3-view radiographies including antero-posterior, lateral, and open mouth views ${ }^{7}$. Previous report has shown three main reasons for delayed or missed diagnosis of cervical spine injuries ${ }^{6}$. Misinterpretation, inadequate radiological study with a limitation of neck motion, and incomplete set of radiographies were indicated. Among these reasons, incomplete set of radiographies was regarded as the main cause for the incorrect diagnosis of cervical instability like our cases. The performance of dynamic flexion and extension radiographies is recommended, in addition to standard 3-view radiographies and CT scan in conscious patients after excluding unstable bony injuries. Several studies have also found those dynamic radiographies to be a safe and effective method for detecting disco-ligamentous injuries under the condition of intact bony structures on previous static radiographies ${ }^{9,12)}$. When there is a high level of uncertainty related to bony or ligamentous injury in the static radiographies, dynamic flexion and extension radiographies should be avoided until the extent of the lesion is determined by CT scan or MR imaging' ${ }^{6}$.

When adequate flexion and extension motions are possible, dynamic flexion and extension radiographies for the evaluation of cervical instability are associated with a very low false-negative rate ${ }^{2,4)}$. Some authors have recommended the average range of motion in patients judged to have adequate motion was 40.6 degrees (range, 23-58 degrees) ${ }^{12}$. . However, because $30 \%$ of cervical trauma patients have a limitation to flex and extend due to acute neck pain following an accident, the incidence of positive results of dynamic flexion and extension radiographies in emergency rooms is very low $(0.34 \%)^{2,4,12)}$. These patients may have an increased risk of disco-ligamentous injury, and further imaging tools might be suggested ${ }^{24)}$. Fortunately, in our cases, cervical instability could be detected under insufficient motion range (range, 10.4-45.4 degrees) and even in the early period following the accident. Nevertheless, the examination is preferred to be performed under surveillance to avoid neurologic problems when the improvement of neck pain and sufficient neck motion are obtained.

\section{CONCLUSION}

Dynamic flexion and extension radiographies are required 
to exclude the possibility of cervical instability in the patient with cervical trauma in initial or follow-up studies. However, the examination should be performed carefully to avoid neurologic deterioration.

\section{REFERENCES}

1. Alker GJ, Oh YS, Leslie EV, Lehotay J, Panaro VA, Eschner EG: Postmortem radiology of head neck injuries in fatal traffic accidents. Radiology 114:611-617, 1975

2. Gelalis ID, Christoforou G, Arnaoutoglou CM, Politis AN, Manoudis G, Xenakis TA: Misdiagnosed bilateral C5-C6 dislocation causing cervical spine instability: a case report. Cases J 2: 6149, 2009

3. Gerrelts BD, Petersen EU, Mabry J, Petersen SR: Delayed diagnosis of cervical spine injuries. J Trauma 31:1622-1626, 1991

4. Insko EK, Gracias VH, Gupta R, Goettler CE, Gaieski DF, Dalinka MK: Utility of flexion and extension radiographs of the cervical spine in the acute evaluation of blunt trauma. J Trauma 53:426-429, 2002

5. MacDonald RL, Schwartz ML, Mirich D, Sharkey PW, Nelson WR: Diagnosis of cervical spine injury in motor vehicle crash victims: how many X-rays are enough? J Trauma 30:392-397, 1990

6. Platzer P, Hauswirth N, Jaindl M, Chatwani S, Vecsei V, Gaebler C: Delayed or missed diagnosis of cervical spine injuries. J Trauma 61:150-155, 2006

7. Pollack CV Jr., Hendey GW, Martin DR, Hoffman JR, Mower WR: Use of flexion-extension radiographs of the cervical spine in blunt trauma. Ann Emerg Med 38:8-11, 2001

8. Reid DC, Henderson R, Saboe L, Miller JD: Etiology and clinical course of missed spine fractures. J Trauma 27:980-986, 1987

9. Sees DW, Rodriguez Cruz LR, Flaherty SF, Ciceri DP: The use of bedside fluoroscopy to evaluate the cervical spine in obtunded trauma patients. J Trauma 45:768-771, 1998

10. Shah VM, Marco RA: Delayed presentation of cervical ligamentous instability without radiologic evidence. Spine (Phila Pa 1976) 32:E168-174, 2007

11. Vaccaro AR, Hulbert RJ, Patel AA, Fisher C, Dvorak M, Lehman RA Jr., et al: The subaxial cervical spine injury classification system: a novel approach to recognize the importance of morphology, neurology, and integrity of the disco-ligamentous complex. Spine (Phila Pa 1976) 32:2365-2374, 2007

12. Wang JC, Hatch JD, Sandhu HS, Delamarter RB: Cervical flexion and extension radiographs in acutely injured patients. Clin Orthop Relat Res:111-116, 1999 